\title{
Increasing the Engagement of Millennials: Finding Autonomy and Salience in High Workload
}

\section{Ida Ayu Karina Adityanti Manuaba ${ }^{a}$ and Arum Etikariena Hidayat ${ }^{\mathrm{b}}$}

${ }^{a}$ Faculty of Psychology, Universitas Indonesia, Depok, Indonesia; ${ }^{b}$ Department of Industrial and Organizational Psychology, Faculty of Psychology, Universitas Indonesia, Depok, Indonesia

*Corresponding author:

Arum Etikariena Hidayat

Department of Industrial and Organizational Psychology

Faculty of Psychology, Universitas Indonesia

Depok, Jawa Barat Indonesia, 16424

Tel.: +62 217270004

Email address: arum.etikariena@ui.ac.id /arum.hidayat@gmail.com 


\title{
Increasing the Engagement of Millennials: Finding Autonomy and Salience in High Workload
}

\begin{abstract}
This study developed an application for the job-demands-resources (JDR) model of work engagement to test the moderating effects of quantitative workload on the relationship between job autonomy and work engagement in millennials. A cross-sectional study design was employed on 145 millennial employees in Indonesia. The Utrecht Work Engagement Scale (UWES) was used to measure work engagement, the Autonomy Task Characteristic scale was used to measure job autonomy, and the Quantitative Workload Inventory (QWI) was used to measure quantitative workload. Regression analysis based on a simple moderation model was then applied to the results from which it was found that there was a positive and significant moderating effect of quantitative workload on the relationship between job autonomy and work engagement. The results clearly expanded the job demands-resources (JD-R) model and suggested that job autonomy as a job resource had the salience to increase the work engagement of the millennial generation in a high workload (quantitative workload) context. The results of this study provide guidance to organizations in terms of the job demands and job resources to ensure millennial well-being and good job performance in Indonesia.
\end{abstract}

Keywords: millennial, work engagement, job autonomy, quantitative workload, millennial, job resources, job demands

\section{Introduction}

The millennial generation was born between 1980 and 2000 (Meier, Austin, \& Crocker, 2010). In the workplace, the millennials not only want opportunity but also want performance guarantees; that is, this generation expects organizations to provide the right work environment, a good salary and benefits, as well as ongoing training and development, flexibility and freedom, job variation, contact with leaders, and a decent work-life balance. As this generation also prefers challenges, they do not consider organizations that only provide ordinary incentives (Alsop; Espinoza, et al; Byrne; Herbison \& Boseman; Sujansky \& Ferry-Reed in Carpenter \& de Charon, 2014).

The millennial generation make up the largest percentage in the Indonesian workforce. Central Bureau of Statistics' data released in 2016 indicated that of the 160 million people in the workforce, around 62.5 million were from the millennial generation (Triwijanarko, 2016), which is expected to reach more than $40 \%$ by 2020 (Loudenback; Pew Research Center in Hobbs, 2017) surpassing and replacing generation X employees. However, compared to previous generations, the millennial generation has different perspectives and expectations especially in terms of work life and career development.

Previous research had found certain work place phenomena specific to the millennial generation, one of which has been the propensity to "job-hop." A Future Workplace survey on 
"Multiple Generations @ Work" conducted on 1,189 staff and 150 managers found that 91\% of millennials expect to continue in their current job for less than three years, meaning that they expected to have 15-20 different jobs throughout their lives (Kapadia, 2015). Therefore, managing millennials in the workplace has become a challenge as they have different work expectations and work values, are not very loyal to the organization and keep their career choices open (Smith and Galbraith in Buang, Hemdi, \& Hanafiah, 2016).

Dale Carnegie Indonesia conducted a study on millennial employee engagement in 2016 and found that of the 1,200 millennial employees interviewed in six major Indonesian cities, only $25 \%$ were fully engaged in their organization (Triwijanarko, 2016)., with the remaining 75\% not fully engaged in their work and thinking of resigning. Therefore, HR practitioners should be worried about millennial staff retention.

Bakker \& Demerouti (2008) claimed that positive organizational behavior or work engagement as a positively oriented human resource strength could be measured and enhanced to improve overall organizational performance. Organizations nowadays are becoming more aware that employee engagement is vital to overall performance. Rasca (2017), for example, claimed that organizations with highly engaged workforces can increase innovation and productivity, and can also reduce the costs related to hiring and retention. Work engagement has also been found to be indirectly related to burnout (Remo, 2012), and highly engaged employees have been observed to have the motivation to work beyond the basic work demands of the organization (Bakker \& Demerouti, 2008).

Work engagement has been defined as "a positive, fulfilling, work-related state of mind" (Bakker \& Demerouti, 2008) that had three dimensions; vigor, dedication, and absorption. Vigor is the willingness to invest effort, energy, and mental resilience in work and have persistence when faced with difficulties, dedication is experiencing a sense of enthusiasm, pride, and inspiration, even when faced with challenges and significantly high involvement, and absorption is being able to be happily engrossed in one's work so that time seems to pass quickly (Schaufeli in Remo, 2012).

The job demands-resources (JD-R) model has been used to examine employee engagement. Bakker and Demerouti (2008) claimed that this model assumes that: (1) job resources are able to increase work engagement; and (2) the job resources effect on work engagement is strengthened when there are high job demands. That is, as job demands are related to physical, psychological, social, and organizational aspects, when there is high work pressure, an unfavorable physical environment, and high emotional demands, employees can experience work stress (Meijiman \& Mulder in Bakker \& Demerouti, 2007).

This study added to the JD-R model by including the quantitative (work overload) job demands at the task-level of job autonomy, and viewing job resources as the physical, psychological, social, and organizational aspects associated with achieving work objectives, reducing job demands, and stimulating employee growth, learning, and self-development (Bakker \& Demerouti, 2007). 
Job autonomy has been defined as "the degree to which a job provides independence and freedom for employees in scheduling work and determining the work procedures" (Hackman \& Oldham in Robert, 2013). Morgeson and Humphrey (in De Spigelaere, Van Gyes, \& Van Hootegem, 2016) developed three job autonomy measuring instruments; work scheduling, decision making, and work methods. Generally, job autonomy has been seen to be a desirable work feature that is closely related to work motivation (Hackman \& Oldham in Zhang, Jex, Peng, \& Wang, 2016), and employees with high job autonomy have been found to have strong feelings of responsibility toward their work (Bandura, Hackman \& Oldham in Zhang et al., 2016); therefore, job autonomy could be seen to be an important job resource that increases work engagement. Another study also found that job autonomy was a job resource that contributed to the three work engagement dimensions (Schaufeli \& Salanova in Zhang et al., 2016).

Workload is related to job demand and can be measured by working hours, level of production, or even the mental demands at work (Spector \& Jex, 1998). The Quantitative Workload Inventory (QWI) developed by Spector and Jex measured the speed and volume of work employees felt they were doing from which it was found that high workloads tended to induce employee uncertainty about their ability to complete their work, which resulted in anxiety and a tendency to ignore certain work aspects (Spector \& Jex, 1998). Hakanen, Schaufeli, and Ahola (2008) also found that the quantitative workload was a job demand that was able to predict burnout over a three-year period.

The proposed model for this study was based on Bakker and Demerouti's (2008) JD-R model of work engagement, in which the job resources have been found to have a positive impact on work engagement when the job demand is high. As explained, it was assumed that job autonomy was a job resource related to employee work engagement when employees are confronted with a high quantitative workload. Therefore, this study sought to prove the hypothesis that there is a positive and significant moderating effect of quantitative workload on the relationship between job autonomy and work engagement in Indonesian millennials. The research model, therefore, included job autonomy, quantitative workload, and work engagement, as shown in the theoretical simple moderation model diagram in Figure 1.

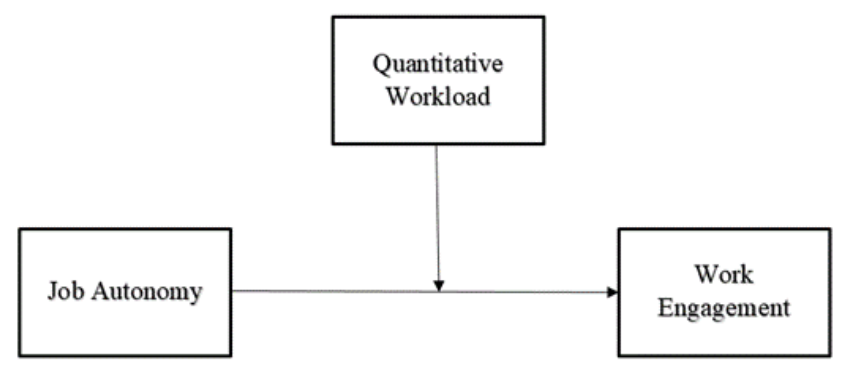

Fig. 1. Proposed Job Autonomy, Quantitative Workload, and Engagement Model 


\section{Method}

\section{Participants}

This study was conducted on 145 millennial employees in Indonesia. All participants were fulltime employees from public and private sector organizations, had been employed in their present organization for at least one year, and had a minimum of a high school graduate degree. The participants were chosen using convenience sampling. Of the participants, $43.45 \%$ were male, most were aged 26 to 30 years old $(58.62 \%)$ and most has been working in their current organization for 2 to 10 years $(71.72 \%)$. A majority of the participants had bachelor's degrees (76.55\%), followed by master's degrees $(9.66 \%)$, diploma degrees $(5.52 \%)$, and high school diplomas $(8.28 \%)$.

\section{Research Design and Procedures}

This study utilized quantitative methods and had a cross-sectional design. The data were collected using a questionnaire made up of the Utrecht Work Engagement Scale (UWES), the Autonomy Task Characteristic scale, and the QWI to respectively measure work engagement, job autonomy, and quantitative workload. The measuring instruments used in the study to measure work engagement and job autonomy were adapted from a previous study, while the measuring instrument used to measure the quantitative workload was translated from English to Bahasa and validated by Industrial and Organizational (I/O) practitioners.

Invitations to be involved in the survey were sent via online messaging on several social media sites and online groups, in which a survey link was provided to the online website-hosted survey. Each participant received a consent form before completing the questionnaire which explained the purpose of the study and guaranteed data confidentiality. Respondents were also asked to provide their demographic data; gender, age, education level, and tenure. This study gave rewards to the 20 respondents who completed the questionnaire.

\section{Measurement Instruments}

\section{Work engagement}

Work engagement was measured using the UWES developed by Novena (2013), which has three dimensions: Vigor (three items, e.g., "at work I feel bursting with energy"), Dedication (three items, e.g., my work inspired me), and Absorption (three items, e.g., I can be very involved with my work); which were answered on a Likert scale ranging from 1 (never) to 7 (always). The internal consistency (Cronbach's $\alpha$ ) for the UWES was 0.89 .

\section{Job autonomy}

The Autonomy Task Characteristics scale contained in the Work Design Questionnaire from Robert (2013) was used to measure job autonomy, which has three dimensions: Work scheduling (three items, e.g., the work allows me to make my own decisions regarding the scheduling of my work); Decision making (three items, e.g., the work allows me to make many decisions in person); and Work methods (three items, e.g., the work allows me to determine what methods I use to complete my work): which were answered using a Likert scale ranging 
from 1 (strongly disagree) to 6 (strongly agree). The internal consistency (Cronbach's $\alpha$ ) for the scale was 0.91 .

\section{Quantitative workload}

Quantitative workload was measured using the QWI (Five items, i.e., "how often does your job require you to work very fast?") developed by Keating and Cunningham [16], which was answered on a five-point Likert scale indicating how often they experienced the feeling described by each statement ranging from 1 ('less than once per month or never') to 5 ('several times per day'). The internal consistency (Cronbach's $\alpha$ ) for the QWI was 0.92 .

\section{Data Analysis}

The model in Figure 1 was analyzed using the moderation process analysis developed by Hayes (model 1). This statistical analysis method was selected because of its ability to test the role of the moderator. The hypothesized model was tested against data from the samples using IBM SPSS Statistics 24.0. Table 1 shows the demographic data distribution.

\section{Results}

Table 1 shows the means, standard deviations, and correlations for all variables. Correlation analysis was employed to describe the linear relationships between the variables in the model. It was found that there was a correlation between job autonomy and work engagement $(\mathrm{r}=$ $-.77)$, and between quantitative workload and work engagement $(\mathrm{r}=.85)$.

Table I. Means, Standard Deviation, and Correlations for All Variables

\begin{tabular}{|c|c|c|c|c|c|c|c|c|c|}
\hline & $\mathbf{M}$ & SD & 1 & 2 & 3 & 4 & 5 & 6 & 7 \\
\hline Work & 5.2 & 0.1 & 1.00 & & & & & & \\
\hline Engagement & 7 & 2 & & & & & & & \\
\hline Job & 4.4 & 0.1 & $-0.77 * *$ & 1.00 & & & & & \\
\hline Autonomy & 1 & 4 & & & & & & & \\
\hline Quantitative & 2.8 & 0.3 & $0.85 * *$ & $-0.91 * *$ & 1.00 & & & & \\
\hline Workload & 0 & 2 & & & & & & & \\
\hline Gender & $\begin{array}{r}1.5 \\
7\end{array}$ & $\begin{array}{r}0.5 \\
0\end{array}$ & -0.01 & 0.11 & $\begin{array}{r}-0.0 \\
8\end{array}$ & 1.00 & & & \\
\hline Age & $\begin{array}{r}28 . \\
02\end{array}$ & $\begin{array}{r}3.2 \\
2\end{array}$ & -0.01 & -0.02 & 0.01 & $\begin{array}{r}-0.1 \\
6\end{array}$ & 1.00 & & \\
\hline Education & $\begin{array}{r}2.8 \\
8\end{array}$ & $\begin{array}{r}0.6 \\
9\end{array}$ & -0.02 & -0.03 & 0.05 & $0.21 *$ & 0.01 & 1.00 & \\
\hline Tenure & $\begin{array}{r}3.2 \\
6\end{array}$ & $\begin{array}{r}2.4 \\
6\end{array}$ & 0.01 & -0.09 & 0.05 & $\begin{array}{r}-0.0 \\
2\end{array}$ & $0.58 * *$ & $\begin{array}{r}-0.0 \\
4\end{array}$ & $\begin{array}{r}1.0 \\
0\end{array}$ \\
\hline
\end{tabular}

a. **Correlation is significant at the 0.01 level (2-tailed).

b. *Correlation is significant at the 0.05 level (2-tailed)

The hypothesis in this study predicted that quantitative workload was a significant moderator for the relationship between job autonomy and work engagement. Figure 2 presents the results for the moderation model, in which the independent variable, the moderator variable (quantitative workload), and the interaction variables (job autonomy $\times$ quantitative workload) were entered to predict work engagement. 
As shown in the statistical diagram for the PROCESS model 1, job autonomy was observed to have a significant effect on work engagement $(b=-.79, \mathrm{SE}=.21,95 \% \mathrm{CI}=-1.20$ to -.37$)$, quantitative workload had a significant effect on work engagement $(b=-.63, \mathrm{SE}=.23,95 \%$, $\mathrm{CI}=-1.09$ to -.17 ), and there was a positive and significant moderating effect of quantitative workload on the relationship between job autonomy and work engagement $(b=.23, \mathrm{SE}=.06$, $95 \% \mathrm{CI}=.12$ to .35$)$.

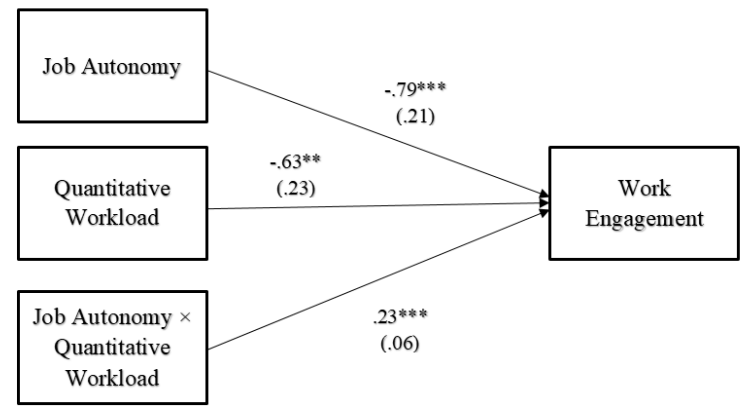

Fig. 2. Results of the moderation model

In essence, the results in Table 2 indicated that the interaction between job autonomy and quantitative workload positively and significantly affected work engagement. The 95\% confidence interval for the moderation effect of quantitative workload on the relationship between job autonomy and work engagement ranged from .12 to .35; therefore, the research hypothesis was supported.

Table II. Interactions between Job Autonomy and Quantitative Workload on Work Engagement

\begin{tabular}{ccccccc}
\hline & $b$ & $S E$ & $t$ & $p$ & \multicolumn{2}{c}{ Bootstrap 95\% } \\
\hline $\begin{array}{c}\text { Job Autonomy X } \\
\text { Quantitative Workload }\end{array}$ & .23 & .06 & 4.03 & $<.001$ & .12 & .35 \\
\hline $\begin{array}{c}\text { Dependent variable: } \\
\text { Work engagement }\end{array}$ & & & & & & \\
\hline
\end{tabular}

\section{Discussion and Conclusion}

This study found that quantitative workload significantly moderated the relationship between job autonomy and work engagement in millennial employees in Indonesia. In particular, job autonomy was found to have a positive impact on work engagement when the quantitative workload was high, which indicated that when millennial employees in Indonesia have high quantitative workloads, they have high work engagement if they have job autonomy, which supported the research hypothesis.

When analyzing these results with the two assumptions in Bakker and Demerouti (2008), the first result was not in accordance with the first assumption in the JD-R model that job autonomy as a job resource had a significant negative effect on work engagement, which was also found in Listau's (2016) study. In future research, the context of an employee's work should also be 
considered as high job autonomy could be seen as a job demand for certain employees, which could make them feel that they should work harder, which could reduce their personal welfare (Butler, et al.; Hakanen \& Peeters in Listau, 2016).

Previous studies have also highlighted the importance of individual differences on the relationship between job autonomy and work engagement. Langfred and Moye [18], for example, found that job autonomy was a job resource and that its advantage may be increased motivation. When an employee's desire for autonomy is low, however, increasing job autonomy could be potentially harmful to employee well-being (Parker et al. in Zhang et al., 2016). Therefore, future research could consider a combination of both job resources and personal resources to predict work engagement when using the original JD-R model. The model suggests that personal resources (e.g., self-efficacy, hope, optimism, and resilience) can also predict employee motivation and buffer the unfavorable effects of job demand Bakker \& Demerouti, 2014). A previous longitudinal study by Xanthopoulou, Bakker, Demerouti, and Schaufeli (in Bakker \& Demerouti, 2014) also observed that personal resources had a reciprocal relationship with job resources and work engagement, that personal resources and work engagement simultaneously could affect job resources, and that job resources could also affect personal resources and work engagement.

The third result from the present study was in accordance with the second JD-R model assumption that there is an increasing job autonomy coefficient when interacting with the quantitative workload, which in turn affects work engagement. These results, therefore, supported the supposition that job resources can be more meaningful when there are high job demands. These findings clearly expanded the JD-R model of work engagement as the present study showed that there was an interaction between job demand and job resource in predicting work engagement, which suggested that the interaction between job autonomy as a job resource and quantitative workload as a job demand could increase millennial work engagement; that is, job autonomy becomes more salient and could lead to work engagement when millennial employees are confronted with a high workload because it leads to goal accomplishment (Hobfoll in Bakker \& Demerouti, 2008).

The results of this study also provide new insights for the organization about millennial engagement, millennial values, and millennial work expectations. Therefore, managers could consider redesigning job demands and job resources to better fit the requirements of Indonesian millennial employees to better ensure employee well-being and job performance. However, managers also need to carefully consider both the nature of the individuals and the nature of the task to prevent burnout.

As this study may have been subject to common method bias, future studies could use a larger sample to better represent the millennial employee population in Indonesia. A longitudinal design could also be used to empirically test the causal relationships between job autonomy and work engagement. 


\section{References}

Bakker, A. B., \& Demerouti, E. (2008). Towards a model of work engagement. Career development international, 13(3), 209-223.

Bakker, A. B., \& Demerouti, E. (2007). The job demands-resources model: State of the art. Journal of managerial psychology, 22(3), 309-328.

Bakker, A. B., \& Demerouti, E. (2014). Job demands-resources theory. Wellbeing: A complete reference guide, $3,1-28$.

Buang, F. H., Hemdi, M. A. and Hanafiah, M. H. (2016). Job Hopping Attitude and Turnover Intention of Gen $Y$ Hotel Employees: A Review and Research Agenda. In Social Sciences Postgraduate International Seminar (SSPIS), 15 December 2016.

Carpenter, M. J., \& de Charon, L. C. (2014). Mitigating multigenerational conflict and attracting, motivating, and retaining millennial employees by changing the organizational culture: A theoretical model. Journal of Psychological Issues in Organizational Culture, 5(3), 68-84.

Hakanen, J. J., Schaufeli, W. B., \& Ahola, K. (2008). The Job Demands-Resources model: A three-year crosslagged study of burnout, depression, commitment, and work engagement. Work \& Stress, 22(3), 224-241.

Hobbs, H. L. (2017). A qualitative study of millennials in the workplace: Gaining their long-term employment in news media firms in North Alabama (Doctoral dissertation). Florida Institute of Technology, Florida.

Kapadia, K. D. (2015). Study on generational diversity at workplace and mitigating the conflicts arising on account of generational differences amongst them. International Journal of Management \& Behavioural Sciences (IJMBS), 6(11), 77-83.

Keating, A. and Cunningham, C. J. L. (2016). Active or passive? an examination of the relationship between the valence of work experiences and choice of recovery strategy (Master thesis). University of Tennessee, Tennessee.

Listau, K. T. (2016). Work engagement: A double-edge sword? A study on the relationship between work engagement, job resources, and the work-home interaction (Master thesis). Norwegian University of Science and Technology, Norwegia.

Langfred, C. W., \& Moye, N. A. (2004). Effects of task autonomy on performance: an extended model considering motivational, informational, and structural mechanisms. Journal of applied psychology, 89(6), 934.-945.

Meier, J., \& Crocker, M. (2010). Generation Y in the workforce: Managerial challenges. The Journal of Human Resource and Adult Learning, 6(1), 68.

Novena, M. M. (2013). Intervention program to improve work engagement in XYZ company based on variable procedural justice, psychological hardiness and commitment to change (Master thesis). Universitas Indonesia, Depok.

Rasca, L. (2017, July). Human resources challenges for the 21st century. In Proceedings of the International Conference on Business Excellence (Vol. 11, No. 1, pp. 475-481).

Remo, N. (2012). Comparing Two Models of Employee Engagement: An Examination of Antecedents and Outcome Variables (Doctoral dissertation). University of Windsor, Ontario.

Robert. C. (2013). The effect of job autonomy and autonomy support towards turnover intention through mediation of psychological empowerment: Case study on information technology workers at four companies (Unpublished undergraduate mini thesis). Universitas Indonesia, Depok.

Spector, P. E., \& Jex, S. M. (1998). Development of four self-report measures of job stressors and strain: interpersonal conflict at work scale, organizational constraints scale, quantitative workload inventory, and physical symptoms inventory. Journal of occupational health psychology, 3(4), 356-367.

Triwijanarko, R. (2016). Hanya 25\% Karyawan Millennials yang Loyal dengan Kantornya. Retrieved from musketeers.com/karyawan-millenial-yang- loyal.

Zhang, W., Jex, S. M., Peng, Y., \& Wang, D. (2017). Exploring the effects of job autonomy on engagement and creativity: The moderating role of performance pressure and learning goal orientation. Journal of Business and Psychology, 32(3), 235-251. 